\title{
Corrigendum
}

\section{A guided tabu search for the heterogeneous vehicle routeing problem}

\author{
CD Tarantilis ${ }^{1}$, EE Zachariadis ${ }^{2}$ and CT Kiranoudis ${ }^{2}$ \\ ${ }^{1}$ Athens University of Economics and Business, Athens, Greece; \\ and ${ }^{2}$ National Technical University of Athens, Athens, Greece
}

Journal of the Operational Research Society (2008) 59, 1698-1699. doi:10.1057/palgrave.jors.2602539

Correction to: Journal of the Operational Research Society (2008) 59, 1659-1673. doi:10.1057/palgrave.jors.2602504

Further examination on the heterogeneous fixed fleet vehicle routeing problem (HFFVRP) revealed an error on the solution reported for the benchmark Problem 13 with the fleet configuration $F C_{\mathrm{G}}$. This error was caused by inappropriately accessing the benchmark instance file. We would like to apologize for any inconvenience caused by the aforementioned oversight.
The GTS algorithm was applied again for the benchmark Problem 13 with the $F C_{\mathrm{G}}$ fleet configuration. The cost of the best solution obtained is equal to 1491.86 , and not 1461.24 as reported in the first row of Table 6 . The CPU time required for generating the best solution is $53 \mathrm{~s}$. Following this, the GTS method produced four new best solutions and reached the solution quality achieved by the LBTA in all four of the other benchmark instances with the $F C_{\mathrm{G}}$ fleet configuration.

The analytic solution of Problem 13 with the $F C_{\mathrm{G}}$ fleet configuration is provided in the corrected version of Table B-1. Furthermore, the structures of the solutions are illustrated in the corrected version of Figure 8. Note that only the solution shape of Problem 13 has changed.

Table B-1 Analytic solution of benchmark Problem 13, with the $F C_{\mathrm{G}}$ fleet configuration

\begin{tabular}{|c|c|c|c|c|c|c|}
\hline Route & $\begin{array}{l}\text { Customer } \\
\text { sequence }\end{array}$ & $\begin{array}{l}\text { Vehicle } \\
\text { type }\end{array}$ & $\begin{array}{c}\text { Vehicle } \\
\text { variable cost }\end{array}$ & Demand & Distance & Cost \\
\hline 1 & 03048214736372015529450 & $\mathrm{~F}$ & 3.2 & 200 & 101.109 & 323.549 \\
\hline 2 & 025310 & $\mathrm{C}$ & 1.2 & 39 & 88.789 & 106.547 \\
\hline 3 & 0492418500 & $\mathrm{D}$ & 1.7 & 67 & 83.977 & 142.761 \\
\hline 4 & 01434241230 & $\mathrm{D}$ & 1.7 & 68 & 83.936 & 142.691 \\
\hline 5 & 0141138100 & $\mathrm{E}$ & 2.5 & 118 & 79.495 & 198.738 \\
\hline 6 & 0222820 & $\mathrm{D}$ & 1.7 & 67 & 64.511 & 109.669 \\
\hline 7 & 034432939260 & $\mathrm{E}$ & 2.5 & 119 & 62.967 & 157.418 \\
\hline 8 & $\begin{array}{lllllll}0 & 27 & 13 & 19 & 35 & 70\end{array}$ & $\mathrm{D}$ & 1.7 & 69 & 62.649 & 106.503 \\
\hline 9 & 0163360 & $\mathrm{D}$ & 1.7 & 65 & 45.841 & 77.930 \\
\hline 10 & 0846340 & $\mathrm{D}$ & 1.7 & 62 & 33.047 & 56.180 \\
\hline 11 & 01740120 & $\mathrm{D}$ & 1.7 & 69 & 31.952 & 54.318 \\
\hline 12 & 040 & $\mathrm{~B}$ & 1.1 & 30 & 14.142 & 15.556 \\
\hline Total cost & & & & & & 1491.859 \\
\hline
\end{tabular}




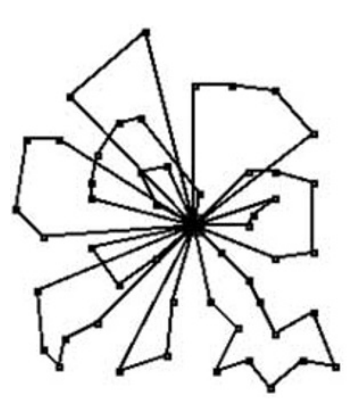

Problem 13

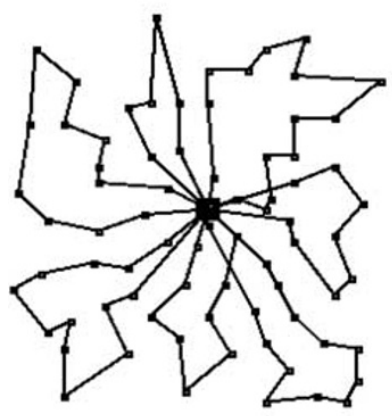

Problem 17

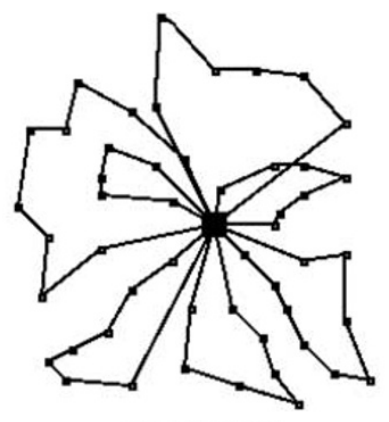

Problem 14

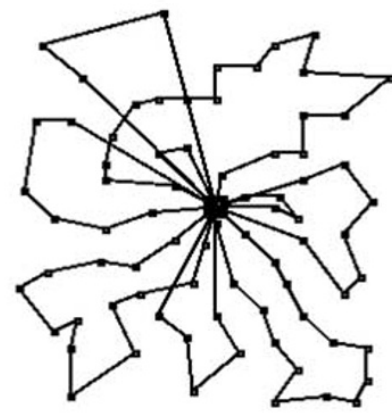

Problem 18

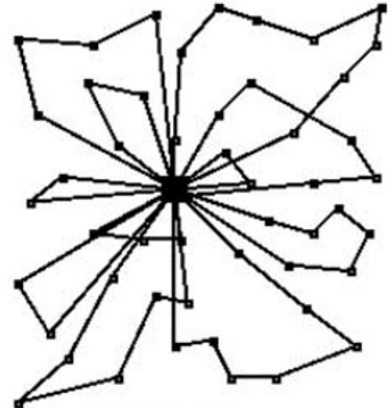

Problem 15

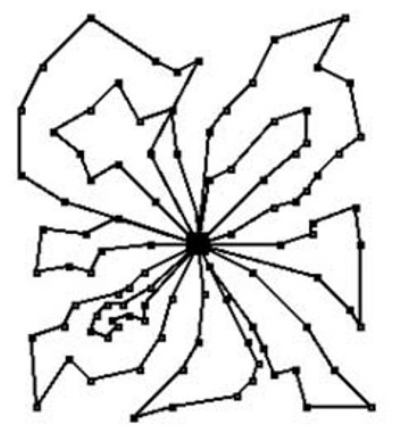

Problem 19

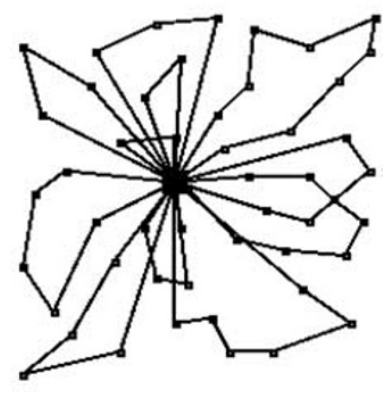

Problem 16

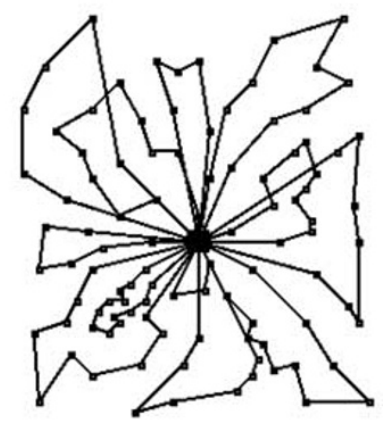

Problem 20

Figure 8 GTS solutions for the examined benchmark instances with the $F C_{\mathrm{G}}$ fleet configuration. 